\title{
Interpretação constitucional e a inovação sumular da estabilidade provisória da gestante nos contratos a prazo determinado
}

\author{
Constitutional interpretation and sumular innovation on pregnant's stability \\ in temporary contracts
}

\author{
Alexei Almeida ChAPPer ${ }^{\mathrm{a}}$
}

\begin{abstract}
RESUMO
Propósitos e consequências conformam o centro da polêmica discussão entre Antonin Scalia e Stephen Breyer sobre a interpretação constitucional na democracia norte-americana. A racionalidade das decisões judiciais e a interpretação sistemática do Direito são fundamentais para a adequada aplicação das normas e cumprimento dos fins constitucionais. No entanto, a neurociência demonstra que pré-condições emocionais e vieses de interpretação afetam o pensamento, e, por conseguinte, a subjetividade do julgador. Tais vieses podem conduzir a arbitrariedades, sobretudo, na definição judicial de propósitos e consequências, o que é contrário ao ideal democrático. Neste contexto, o presente artigo examina o recente entendimento jurisprudencial do Tribunal Superior do Trabalho acerca da estabilidade provisória da gestante nos contratos a prazo determinado. Sintetiza-se o debate entre as correntes do originalismo (Scalia) e do evolucionismo (Breyer) da interpretação constitucional, propondo a combinação de ambas para superar os vieses cognitivos, evitar arbitrariedades e realizar os objetivos constitucionais.
\end{abstract}

Palavras-chave: Evolucionismo. Estabilidade. Gestante. Interpretação constitucional. Originalismo.

\begin{abstract}
Purposes and consequences form the center of the discussion between Stephen Breyer and Antonin Scalia on constitutional interpretation in American democracy. The rationality of judgments and systematic interpretation of law are essential to the proper application of standards and compliance with the constitutional purpose. However, Neuroscience demonstrates that pre-conditions and emotional interpretation bias affects thinking, and therefore, the subjectivity of the judging. Such biases may lead to arbitrariness, especially in the judicial definition of purpose and consequences, which is contrary to the democratic ideal. In this context, this article examines the recent jurisprudential understanding of the Superior Labor Court of Brazil on the stability of the pregnant woman in temporary contracts. It also summarizes the debate between originalism (Scalia) and evolutionism (Breyer) on judicial interpretation, proposing the combination of both to overcome cognitive biases, avoid arbitrariness and perform the constitutional objectives.

Keywords: Evolutionism. Stability. Pregnant. Constitutional interpretation. Originalism.
\end{abstract}

\section{INTRODUÇÃO}

Tomando por base uma questão trabalhista concreta - estabilidade provisória da empregada gestante em contratos de trabalho a prazo determinado -, analisase o problema indicado em epígrafe sob as distintas perspectivas de um juiz que adota a teoria evolucionista de interpretação judicial (Breyer) e de outro que segue a visão originalista de interpretação judicial (Scalia).
A questão é polêmica e passa a ser objeto de discussão a contar da recente inovação da Súmula 244 do TST. Como se pode justificar ou afastar a correção desta posição jurisprudencial a partir da interpretação constitucional originalista (Scalia) ou da interpretação judicial evolucionista (Breyer) do art. 10, II, "b" da Constituição da República?

O TST tem legitimidade para inverter a interpretação original da Constituição por meio de uma Súmula e

\footnotetext{
a Doutorando e Mestre em Direito (pesquisador-bolsista CAPES). Professor visitante e especialista em Direito e Processo do Trabalho na Pós-Graduação da PUCRS.<alexeichapper@hotmail.com>.
} 
determinar que também seja assegurada a estabilidade provisória às empregadas gestantes nos contratos a prazo determinado? Este tipo de intervenção cabe ao Poder Judiciário ou é preciso aguardar pelo Poder Legislativo? O que é mais efetivo?

A proposta, portanto, é abordar um contundente problema trabalhista gerado pela jurisprudência uniformizada pelo TST a partir da inserção do item III à Súmula 244 deste Tribunal.

Qual a visão da teoria originalista/textualista (Scalia)? Como um juiz evolucionista/desenvolvimentista (Breyer) se posicionaria sobre esta situação controvertida? Posições filosóficas distintas em relação à interpretação jurídica sempre significam decisões judiciais antagônicas? Ou será que, a partir de diferentes premissas filosóficas, um juiz originalista poderia chegar à mesma decisão de um juiz evolucionista? Até que ponto o pensamento filosófico do juiz acerca do Direito define o modo como são lidas as normas constitucionais e produzidas as decisões judiciais?

\section{INTERPRETAÇÃO CONSTITUCIONAL: $O$ DEBATE SCALIA $\times$ BREYER E A IMPERIOSA SUPERAÇÃO DOS VIESES DE COGNIÇÃO NA TOMADA DE DECISÃO}

Destaca-se no atual cenário jurídico norteamericano o debate entre Antonin Scalia e Stephen Breyer, ambos Juízes da Suprema Corte americana. De um lado do conflito, originalistas/textualistas, representados por Scalia. No outro extremo, evolucionistas/desenvolvimentistas, liderados por Breyer.

Texto, história, tradição e os precedentes são ferramentas suficientes para a interpretação constitucional (originalistas)? Ou a melhor decisão deve também avaliar propósitos e consequências (nãooriginalistas)? Nesse contexto, como resolver o problema dos vieses de cognição no momento da tomada de decisão?

Estes questionamentos são desenvolvidos em consonância com pesquisas científicas que comprovam a existência de vieses e automatismos na tomada de decisões humanas. Os pontos centrais defendidos pelas correntes do Originalismo e do Evolucionismo servem de base para o fortalecimento da racionalidade das decisões e da interpretação sistemática das normas com o propósito de controlar da melhor forma possível a insegurança jurídica e a incidência dos vieses cognitivos no momento da decisão judicial e da interpretação da Constituição.

\subsection{Originalismo e evolucionismo: combinação para a superação dos vieses de interpretação}

Ao interpretar a Constituição da República, é papel dos juízes ponderar propósitos e consequências como instrumentos para a fundamentação das decisões? O juiz deve aplicar a ordem jurídica ou tentar fazer justiça? Porém, propósitos e consequências não acabam conduzindo o julgador a um grau extremo de subjetividade?

Em debate com Antonin Scalia, Stephen Breyer assevera com bastante franqueza que toda decisão judicial está carregada de algum grau de subjetividade e, precisamente por isso, propósitos e consequências devem ser enfatizados na decisão, sobretudo, nos chamados casos difíceis ${ }^{1}$. Neste sentido, a Suprema Corte deve atuar como "patrulheira das fronteiras e limites criados pela Constituição"2.

Breyer propõe uma peculiar comparação entre a interpretação constitucional e a leitura de uma partitura musical. Nas suas palavras, "no particular theory guarantees that the interpreter can fully capture the composer's intent. It makes sense to ask a musician to emphasize one them more than another" 3 . Destarte, da mesma forma que o músico não apreende completamente a intenção do compositor, não seria possível realmente capturar a intenção do legislador no momento da interpretação.

Os originalistas/textualistas, segundo Breyer, conferem destaque apenas ao texto, à história, à tradição e aos precedentes, mas não expõem suas interpretações sobre os propósitos e as consequências, em que pese essa análise seja feita sem, todavia, constar da fundamentação das decisões. Sobretudo, ao considerarmos a incidência das emoções e dos vieses de interpretação.

De fato, "nossas emoções têm uma mente própria que pode ter opiniões bastante independentes de nossa mente racional" 4 .

O neurocientista David Eagleman ilustra uma variedade de vieses cognitivos, chegando a dizer que "os cérebros são como democracias representativas":

Os cérebros são como democracias representativas. São formados de especialistas múltiplos e sobrepostos que ponderam e competem sobre diferentes decisões. Como supôs corretamente Walt Whitman, somos grandes e abrigamos multidões. E estas multidões estão presas a uma batalha crônica.

Há um diálogo contínuo entre as diferentes facções de seu cérebro; cada um compete para controlar o canal único a seu comportamento. Consequentemente, você pode realizar proezas estranhas de discutir consigo mesmo, xingando-se e convencendo-se a fazer alguma coisa - proezas que os computadores modernos simplesmente não realizam. ${ }^{5}$ 
Neste sentido, a justificação de propósitos e consequências, em vez de aumentar a subjetividade do julgamento, serviria, na verdade, como mais um meio de exame da subjetividade das decisões judiciais. Sem segredos, a decisão deve explicitar e explicar exatamente os motivos que foram determinantes, inclusive propósitos e consequências. E isso é salutar em uma democracia ${ }^{6}$.

Scalia responde que o problema de propósitos e consequências é que estas ferramentas de interpretação "convidam a um julgamento subjetivo" do juiz. Limitações aos propósitos genéricos também são parte dos próprios propósitos dos estatutos normativos ${ }^{7}$.

E o mesmo ocorre com as consequências: a interpretação normativa não pode se reduzir às sensações do juiz, quer dizer, se gosta das consequências interpreta de uma forma e se não gosta interpreta de outro modo ${ }^{8}$.

Em tom bem-humorado, Scalia simplifica que a "Constituição não é um organismo vivo, é um texto legal". Sustenta ser evidente que a norma constitucional deve se adaptar às transformações da realidade, como, por exemplo, as novas tecnologias.

Porém, o contexto em que a escolha normativa foi tomada pelo legislador não pode ser ignorado na interpretação atual do estatuto. São exemplos americanos: a pena de morte, o aborto e o casamento homossexual. Para mudar estas decisões legislativas não se deve usar a interpretação constitucional, e sim a legislação: mudar a legislação, de acordo com Scalia, privilegiando, assim, a democracia ${ }^{9}$.

Veja-se a explicação do próprio Antonin Scalia sobre a chamada interpretação textualista e o papel dos juízes:

\begin{abstract}
The philosophy of interpretation I have described above is known as textualism. In some sophisticated circles, it is considered simpleminded - 'wooden', 'unimaginative', 'pedestrian'. It is none of that. To be a textualist in good standing, one need not to be dull to perceive the broader social purposes that a statute is designed, or could be designed, to serve; or too hidebound to realize that new times require new laws. One need only hold the belief that judges have no authority to pursue those broader purposes or write those new laws. ${ }^{10}$
\end{abstract}

Apesar do argumento originalista, enfatizando o papel do legislador e abstendo o juiz do compromisso com propósitos e consequências, não se pode aceitar "cascatas de conformidade" no que se refere ao cumprimento dos objetivos estabelecidos pela Constituição $^{11}$. O Poder Judiciário também integra e representa o Estado, devendo, pois, assumir uma "atuação estatal indutora" para a promoção e realização dos direitos fundamentais e dos fins constitucionais ${ }^{12}$.

Entretanto, igualmente imprescindível um maior controle sobre a subjetividade do julgador e da jurisprudência sumulada, especialmente em razão dos recentes estudos sobre o funcionamento do cérebro e "os pronunciados riscos de enviesamentos ("biases") na interpretação do mundo e, nessa medida, na compreensão do Direito" 13 .

Sendo assim, Juarez Freitas chama a atenção para "um dos maiores desafios, no âmbito da hermenêutica jurídica". Trata-se de "evitar os erros oriundos de vieses implícitos e explícitos, coibindo as arbitrariedades por ação ou omissão" a fim de "reduzir as falhas cognitivas" e explicitar "as predisposições subjacentes à conformação do significado normativo". Ainda segundo o autor, "o importante é desvendar, cada vez mais, os vieses e desvios cognitivos, no intuito de substituir aquelas predisposições que bloqueiam as escolhas intertemporalmente razoáveis" ${ }^{14}$.

\section{INTERPRETAÇÃO CONSTITUIONAL E A INOVAÇÃO DA SÚMULA 244, III, DO TRIBUNAL SUPERIOR DO TRABALHO}

Até a alteração da Súmula 244, em setembro de 2012, o TST havia firmado o entendimento jurisprudencial segundo o qual a estabilidade provisória da gestante não seria compatível com a contratação a prazo determinado. De acordo com as previsões da CLT, excepcionalmente, o contrato de trabalho pode ser celebrado com termo certo. E a terminação normal destes contratos evidencia a caducidade do negócio jurídico, e não sua resilição arbitrária ou sem justa causa ${ }^{15}$.

Noutras palavras, esta interpretação normativa decorria do fato de que o término normal de um contrato de trabalho celebrado com termo prefixado, evidentemente, não decorre de despedida injusta ou sem justa causa por parte do empregador. O que há é a própria caducidade, isto é, a morte natural do contrato de trabalho sem surpresa para os contratantes.

Neste sentido, o Tribunal Superior do Trabalho publicou, no ano 2000, a Orientação Jurisprudencial 196 da primeira Seção de Dissídios Individuais. Segundo a antiga orientação não se assegura à empregada gestante a garantia de emprego "na hipótese de admissão mediante contrato de experiência, visto que a extinção da relação de emprego, em face do término do prazo, não constitui dispensa arbitrária ou sem justa causa".

Esta interpretação constitucional foi mantida, em 2005, com o cancelamento e respectiva inserção da OJ 196 à redação anterior da Súmula 244 do TST. 
Todavia, em 2012, a interpretação foi completamente invertida. Leia-se a redação atual da Súmula 244 do TST:

SÚMULA № 244 DO TST. (redação do item III alterada na sessão do Tribunal Pleno realizada em 14.09.2012) - Res. 185/2012, DEJT divulgado em 25, 26 e 27.09.2012. GESTANTE. ESTABILIDADE PROVISÓRIA

I - O desconhecimento do estado gravídico pelo empregador não afasta o direito ao

pagamento da indenização decorrente da estabilidade (art. 10, II, "b" do ADCT).

II - A garantia de emprego à gestante só autoriza a reintegração se esta se der durante o período de estabilidade. Do contrário, a garantia restringese aos salários e demais direitos correspondentes ao período de estabilidade.

III - A empregada gestante tem direito à estabilidade provisória prevista no art. 10, inciso II, alinea " $b$ ", do Ato das Disposições Constitucionais Transitórias, mesmo na hipótese de admissão mediante contrato por tempo determinado. [grifou-se]

A inserção do item III à Súmula supracitada inverteu completamente o entendimento jurisprudencial anteriormente firmado pelo Tribunal. A nova interpretação constitucional do ADCT é no sentido de que não há exclusão expressa da aquisição de estabilidade provisória em razão da celebração do contrato ter sido concretizada com prazo determinado. Decisões do STF também são apontadas para justificar esta drástica transição interpretativa ${ }^{16}$.

Naturalmente, a CLT prevê que as partes contratantes podem decidir que o tempo de afastamento do empregado não será computado no prazo normal do contrato a termo certo. Contudo, sem este acordo contratual não há razão jurídica para forçar a extensão indevida do prazo normal previsto para a vigência do contrato a termo. "Se for ajustado entre as partes que o tempo de afastamento não será computado para o término do contrato de trabalho, deve ser observada a regra" do artigo 472, $\S 2^{\circ}$, da CLT. "Do contrário, o contrato de trabalho termina no último dia pactuado, independentemente do tempo em que o empregado ficará afastado" 17 .

Concorde-se ou não com o novo conteúdo da Súmula 244, o fato é que o TST parece adotar a chamada teoria evolucionista de interpretação constitucional. A Constituição não proíbe que a legislação venha a reconhecer estabilidade provisória à gestante em contrato a prazo determinado.

Todavia, o texto constitucional deixa claro que a estabilidade provisória da gestante decorre da vedação à dispensa arbitrária ou sem justa causa a partir da confirmação da gravidez até cinco meses após o parto $^{18}$. O final normal de um contrato de experiência, por exemplo, jamais será dispensa arbitrária ou sem justa causa ${ }^{19}$. Uma interpretação originalista da questão não autorizaria tal inovação da ordem normativa com base no texto da Constituição.

Por outro lado, enfatizando a dignidade e a proteção da personalidade humana (gestante e nascituro), o Tribunal Superior superou a limitação textual do ADCT para efetivamente alterar a ordem jurídica vigente por meio de uma súmula sem caráter vinculante. Nada obstante, "a orientação do TST pode implicar que as empresas não contratem mulheres em contratos de prazo determinado" 20 .

\section{CONCLUSÃO}

Nenhum dos extremos pode ser dado como satisfatório: nem Originalismo, nem Evolucionismo são capazes de promover os fins constitucionais e controlar a incidência dos vieses de interpretação. $\mathrm{O}$ Originalismo não admite a subjetividade das decisões e o Evolucionismo radical pode levar à manipulação injusta do Direito.

É preciso segurança jurídica e previsibilidade formal, evitando ao máximo a inserção da subjetividade do julgador na tomada de decisões. No entanto, o estudo dos vieses deixa claro que algum grau de subjetividade está presente em todas as decisões humanas. E, por isso, a fundamentação judicial dos propósitos e consequências é também essencial para controlar a subjetividade inerente a todo julgamento realizado por um juiz humano.

A expectativa é que em cada caso concreto evidencie-se a imperiosa racionalidade sistemática nas decisões em prol da justiça, que, apesar dos indiscutíveis vieses de interpretação, sempre se espera na aplicação do Direito.

A nova redação da Súmula 244 do TST é um reflexo concreto da aplicação da teoria evolucionista de interpretação constitucional. A jurisprudência uniforme foi alterada com base numa releitura do ADCT a partir dos propósitos e valores constitucionais.

\section{REFERÊNCIAS}

ATIYAH, P. S.; SUMMERS, Robert S. Form and substance in Anglo-American Law: a comparative study of legal reasoning, legal theory, and legal institutions. Oxford: Clarendon Press, 1987. BIANCHI, Giuliana. A gravidez e a estabilidade no contrato de trabalho por tempo determinado. In: Jornal Trabalhista Consulex, Brasília: JTb, ano XXIX, n. 1451, 5 nov. 2012. 
BREYER, Stephen. Making our democracy work: a judge's view. Random House, 2011.

BREYER, Stephen. Active liberty. Interpreting our democratic Constitution. New York: Vintage Books, 2005.

DELGADO, Maurício Godinho. Curso de Direito do Trabalho. São Paulo: LTr, 2013.

EAGLEMAN, David. Incógnito: as vidas secretas do cérebro. Rio de Janeiro: Rocco, 2012.

FRANCO FILHO, Georgenor de Souza. Garantia de Emprego da Gestante: o Item III da Súmula no 244 do TST. In: Revista Síntese Trabalhista e Previdenciária, ano XXIV, n. 289.

FREITAS, Juarez. Hermenêutica e desvios cognitivos. Revista de direitos e garantias fundamentais. Vitória, n. 13, p. 277-308, jan.-jun. 2013.

FREITAS, Juarez. A hermenêutica jurídica e a ciência do cérebro: como lidar com os automatismos mentais. Revista Ajuris, n. 130, jun. 2013.

GOLEMAN, Daniel. Inteligênia emocional. Rio de Janeiro: Objetiva, 2001.
MARTINS, Sergio Pinto. Garantia de emprego da gestante no contrato de trabalho de prazo certo. In: STÜRMER, Gilberto; AZEVEDO, André Jobim de; BRAVO, Alvaro Sánchez (Org.). Anais do Congresso Internacional de Direito do Trabalho. Porto Alegre: HS, 2014.

AZEVEDO, André Jobim de; BRAVO, Alvaro Sánchez (Org.). Comentários às Súmulas do TST. São Paulo: Atlas, 2014.

NASCIMENTO, Amauri Mascaro. Curso de Direito do Trabalho. São Paulo: LTr, 2013.

SCALIA, Antonin. A matter of interpretation: federal courts and the law. New Jersey: Princeton University Press.

SCALIA, Antonin; BREYER, Stephen. American Constitution Society. Antonin Scalia and Stephen Breyer debate the Constitution. Disponível em: <www.acslaw.com>. Acesso em: 15 jun. 2014.

SUNSTEIN, Cass. A verdade sobre os boatos: como se espalham e por que acreditamos neles. Rio de Janeiro: Elsevier, 2010.

THALER, Richard; SUNSTEIN, Cass. Nudge: o empurrão para a escolha certa. Rio de Janeiro: Elsevier, 2009.

\section{NOTAS}

${ }^{1}$ SCALIA, Antonin; BREYER, Stephen. American Constitution Society. Antonin Scalia and Stephen Breyer debate the Constitution. Disponível em: <www.acslaw.com>. Acesso em: 15 jun. 2014.

2 BREYER, Stephen. Making our democracy work. Random House, 2011. p. 215.

3 BREYER, Stephen. Active liberty. Interpreting our democratic Constitution. New York: Vintage Books, 2005. "one can understand an interpretation that approaches a great symphony from a 'romantic', as opposed to a'classical', point of view. So might a judge pay greater attention to a document's democratic theme; and so might a judge view the Constitution through a more democratic lens". p. 07.

${ }^{4}$ GOLEMAN, Daniel. Inteligênia emocional. Rio de Janeiro: Objetiva, 2001. p. 16.

${ }^{5}$ EAGLEMAN, David. Incógnito: as vidas secretas do cérebro. Rio de Janeiro: Rocco, 2012. p. 118-119.

${ }^{6}$ SCALIA, Antonin; BREYER, Stephen. American Constitution Society. Antonin Scalia and Stephen Breyer debate the Constitution. Disponível em: $<$ www.acslaw.com $>$. Acesso em: 15 jun. 2014.

7 "In both the English and the American legal systems, statute law is, in several different respects, an inherently more formal type of law. First, statute law has a very high level of 'rank formality': thus it takes priority over all conflicting law (other than constitutional law) including especially judge made law". ATIYAH, P. S.; SUMMERS, Robert S. Form and substance in Anglo-American Law: a comparative study of legal reasoning, legal theory, and legal institutions. Oxford: Clarendon Press, 1987. p. 96.

${ }^{8}$ SCALIA, Antonin; BREYER, Stephen. American Constitution Society. Antonin Scalia and Stephen Breyer debate the Constitution. Disponível em: <www.acslaw.com>. Acesso em: 15 jun. 2014.
${ }^{9}$ SCALIA, Antonin; BREYER, Stephen. American Constitution Society. Antonin Scalia and Stephen Breyer debate the Constitution. Disponível em: <www.acslaw.com>. Acesso em: 15 jun. 2014.

${ }^{10}$ SCALIA, Antonin. A matter of interpretation: federal courts and the law. New Jersey: Princeton University Press. p. 23

${ }^{11}$ SUNSTEIN, Cass. A verdade sobre os boatos: como se espalham e por que acreditamos neles. Rio de Janeiro: Elsevier, 2010. p. 40.

${ }^{12}$ THALER, Richard; SUNSTEIN, Cass. Nudge: o empurrão para a escolha certa. Rio de Janeiro: Elsevier, 2009. p. 5.

${ }^{13}$ FREITAS, Juarez. Hermenêutica e desvios cognitivos. Revista de Direitos e Garantias Fundamentais, Vitória, n. 13, jan.-jun. 2013. p. 277.

${ }^{14}$ FREITAS, Juarez. A hermenêutica jurídica e a ciência do cérebro: como lidar com os automatismos mentais. Revista Ajuris, n. 130, jun. 2013.

${ }^{15}$ DELGADO, Maurício Godinho. Curso de Direito do Trabalho. São Paulo: LTr, 2013. p. 1159.

${ }^{16}$ Cf. RE 600.057 AgR/SC, 23/10/2009. RE 287.905/SC, 29/03/2011. RE 458.807/BA, 11/03/2010. AI 804.574 AgR/DF, 15/092011. BIANCHI, Giuliana. A gravidez e a estabilidade no contrato de trabalho por tempo determinado. Jornal Trabalhista Consulex, Brasília: JTb, ano XXIX, n. 1451,5 nov. 2012. p. 6.

${ }^{17}$ MARTINS, Sergio Pinto. Garantia de emprego da gestante no contrato de trabalho de prazo certo. In: STÜRMER, Gilberto; AZEVEDO, André Jobim de; BRAVO, Alvaro Sánchez (Org.). Anais do Congresso Internacional de Direito do Trabalho. Porto Alegre: HS, 2014. p. 111.

${ }^{18}$ FRANCO FILHO, Georgenor de Souza. Garantia de Emprego da Gestante: o Item III da Súmula no 244 do TST. Revista Sintese Trabalhista e Previdenciária, ano XXIV, n. 289, p. 28.

${ }^{19}$ NASCIMENTO, Amauri Mascaro. Curso de Direito do Trabalho. São Paulo: LTr, 2013. p. 702.

${ }^{20}$ MARTINS, Sergio Pinto. Comentários às Súmulas do TST. São Paulo: Atlas, 2014. p. 147. 